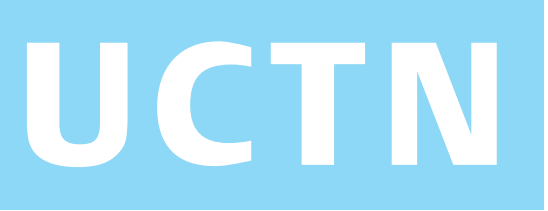

\title{
Successful Prevention of Stent Migration Caused by Placement of a Second Stent
}

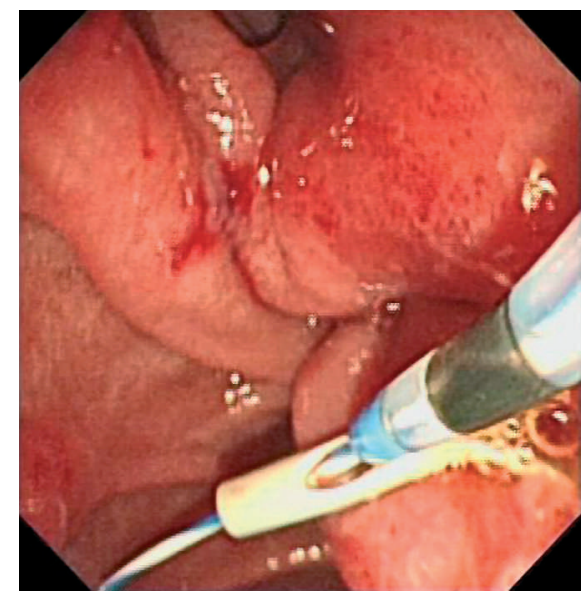

Figure 1 The guide wire is pushed into the duodenum through the lateral hole of the first stent.

Plastic biliary stents are among the most important devices used in therapeutic endoscopic retrograde cholangiopancreatography (ERCP). Stents are used in the treatment of a number of biliary diseases. They can be used curatively in some conditions, such as biliary leaks, or as palliative treatment, as in distal malignant biliary obstruction. Only one stent is required in many of these cases, but patients with some biliary disorders, such as postoperative benign biliary stricture or proximal malignant biliary stricture, may require more than one stent. One of the most important complications of insertion of a second stent is migration of the first stent as the second stent is pushed in. We describe here a simple maneuver which may be used to prevent this problem (Fig.1-3).

The lateral hole in the duodenal part of the first stent is cannulated with a guide wire, using an ERCP catheter. To facilitate this, the edge of the catheter may be curved oppositely as in cannulation in patients with a Billroth II-type gastroenterostomy. Pushing the rigid segment of the guide wire into the duodenum may be more effective. The catheter is then withdrawn, leaving the guide wire in the stent.

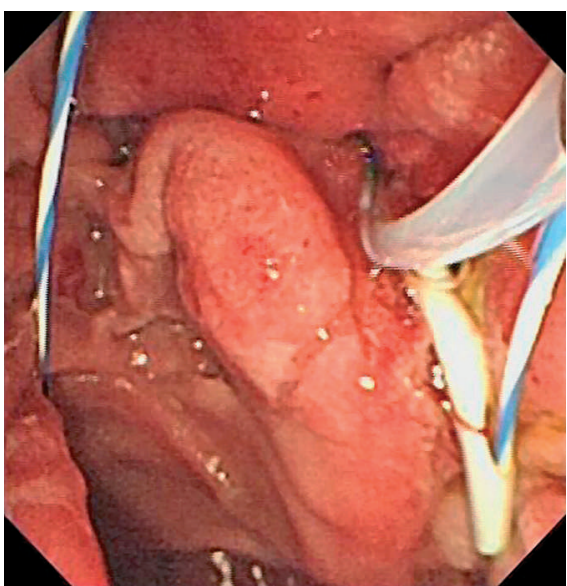

Figure 2 Another guide wire is placed near the first stent using an endoscopic retrograde cholangiopancreatography catheter.

After cannulation of the papilla with the catheter, the second stent can be placed. The guide wire in the first stent prevents its migration during placed of the second stent.

We have used this procedure successfully for placing plastic stents ranging in size from $7 \mathrm{Fr}$ to $10 \mathrm{Fr}$, using a duodenoscope with a working-channel diameter of $4.2 \mathrm{~mm}$. Of course, placement of a $10-\mathrm{Fr}$ stent is more difficult than that of 7-Fr or 8-Fr stents but it is not impossible.

\section{E. Parlak, B. Çiçek, i. Koruk, S. Dişibeyaz, B. Sahin}

Department of Gastroenterology, Turkiye Yuksek Ihtisas Hospital, Ankara, Turkey.

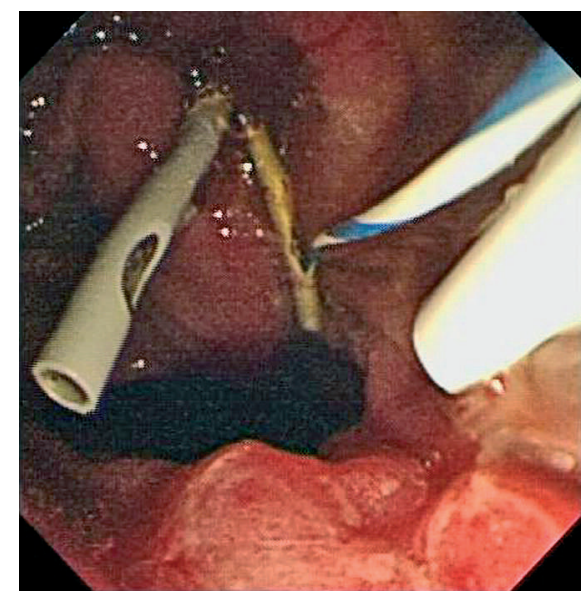

Figure 3 The first guide wire prevents migration of the first stent during placement of the second stent.

\section{Corresponding Author}

\section{E. Parlak, M.D.}

Department of Gastroenterology Turkiye Yuksek Ihtisas Hospital 06100 Yenisehir Ankara Turkey

Fax: $\quad$ +90-312-3124122

E-mail: Eparlak@tr.net 